\title{
Biogenic Volatile Compounds for Plant Disease Diagnosis and Health Improvement
}

\author{
Rouhallah Sharifi ${ }^{1}$ and Choong-Min $\mathbf{R y u}{ }^{2,3 *}$ \\ ${ }^{I}$ Department of Plant Protection, College of Agriculture and Natural Resources, Razi University, Kermanshah, Iran \\ ${ }^{2}$ Molecular Phytobacteriology Laboratory, Infectious Disease Research Center, KRIBB, Daejeon 34141, Korea \\ ${ }^{3}$ Biosystem and Bioengineering Program, University of Science and Technology (UST), Daejeon 34141, Korea
}

(Received on June 30, 2018; Revised on August 26, 2018; Accepted on September 12, 2018)

Plants and microorganisms (microbes) use information from chemicals such as volatile compounds to understand their environments. Proficiency in sensing and responding to these infochemicals increases an organism's ecological competence and ability to survive in competitive environments, particularly with regard to plant-pathogen interactions. Plants and microbes acquired the ability to sense and respond to biogenic volatiles during their evolutionary history. However, these signals can only be interpreted by humans through the use of state-of the-art technologies. Newly-developed tools allow microbe-induced plant volatiles to be detected in a rapid, precise, and non-invasive manner to diagnose plant diseases. Beside disease diagnosis, volatile compounds may also be valuable in improving crop productivity in sustainable agriculture. Bacterial volatile compounds (BVCs) have potential for use as a novel plant growth stimulant or as improver of fertilizer efficiency. BVCs can also elicit plant innate immunity against insect pests and microbial pathogens. Research is needed to expand our knowledge of BVCs and to produce BVC-based formulations that can be used practically in the field. Formulation possibilities include encapsulation and sol-gel matrices, which can be used in attract and kill formulations, chemigation, and seed priming. Exploitation of biogenic volatiles will facilitate

\footnotetext{
*Corresponding author.

Phone) +82-42-879-8229, FAX) +82-42-860-4488

E-mail)cmryu@kribb.re.kr

(c) This is an Open Access article distributed under the terms of the Creative Commons Attribution Non-Commercial License (http:// creativecommons.org/licenses/by-nc/4.0) which permits unrestricted noncommercial use, distribution, and reproduction in any medium, provided the original work is properly cited.
}

Articles can be freely viewed online at www.ppjonline.org. the development of smart integrated plant management systems for disease control and productivity improvement.

Keywords : bacterial volatile, enchapsulation, microbeinduced plant volatiles (MIPVs), non-invasive detection, PGPR

Handling Associate Editor : Lee, Yong Hoon

The 20th century philosopher Ludwig Wittgenstein said, "The limits of my language mean the limits of my world" (Wittgenstein, 1922). By learning the communication systems of other organisms, humans may be able to expand their world view and increase their understanding of other species. Chemical communication language is the syntax of a ubiquitous biological language, and highly diffusible low molecular weight volatile compounds constitute the alphabet of this language (Mithofer and Boland, 2016). Plants and microorganisms release blends of volatile compounds to their surrounding environment. The constituents of volatile blends vary with taxon as well as with organism age and exposure to biotic and abiotic stresses (Jiang et al., 2016; Niinemets and Monson, 2013; Sharifi et al., 2018). Accordingly, volatile blends reflect the presence of emitter organisms and their physiological status, whether healthy or stressed (Niinemets et al., 2013; Sharifi et al., 2018). It is not yet clear whether emitter organisms release volatiles for deliberate communication with neighbors, but receiver organisms have evolved processes for understanding information imparted by volatiles (Heil, 2014; Sharifi and Ryu, 2018a, 2018b).

Biogenic volatiles can thus be considered as infochemicals that act as intra-species, inter-species, and interkingdom signal communications. For example, bacterial 
volatile compounds (BVCs) influence several steps in plant physiological development, from seed germination to harvesting time (Sharifi and Ryu, 2018a) . Biogenic volatiles therefore have potential as novel fertilizers or plant stimulant in modern agriculture. Volatiles can also induce systemic defenses against biotic stress (Chung et al., 2016): and can act as inter- and intra-species signals in plants (Yi et al., 2009), and therefore have potential as novel pesticides. In recent years, biogenic volatiles have been exploited to modulate plant physiology (Sharifi and Ryu, 2016; Song et al., 2015), to detect diseased or stressed plants (Jansen et al., 2011; Niinemets et al., 2013), and to discriminate between bacterial species (Halbfeld et al., 2018; Lough et al., 2017; Spinelli et al., 2012; Wilson et al., 2004).

Biogenic volatiles thus constitute a rich source of information that could be highly valuable in modern precision agriculture. For example, real-time analysis of microbeinduced plant volatiles (MIPVs) could allow rapid, noninvasive detection of plant diseases. Bacterial volatiles also have great potential for application in the field as fertilizers or as inducers of natural plant defenses (Ryu, 2015; Song and Ryu, 2013). However, practical use of biogenic volatiles in the field remains challenging due to their high vapor pressure. Research is lacking into the development of effective application formulations for BVCs. Here, we discuss how slow-release technologies such as microencapsulation and sol-gel could facilitate preparation of BVC formulations amenable to commercial application. The use of BVCs in drip irrigation systems, storage, nurseries, and open fields is also discussed.

Non-invasive diagnosis of diseased plants by volatile analysis

Plant volatiles function as infochemicals for neighboring plants and for other organisms in the phytobiome. Infected or injured plants release blends of volatile compounds that differ from those released by healthy plants (Sharifi et al., 2018). Plant volatiles could be used to detect infected plants during early stages of disease development, earlier than detection was possible using other methods (Aksenov et al., 2014; Cellini et al., 2016; Martinelli et al., 2015; Wilson et al., 2004). Here, we review the most recent developments in non-invasive detection of MIPVs. Gas chromatographymass spectrometry (GC-MS) is a basic analytical method for volatile detection that can be used to measure the relative amount of each compound in volatile emissions. Several methods have been developed for sampling and preconcentration of volatiles from plant samples either in lab or field conditions. In passive (static headspace) sampling methods, volatile traps by absorbent material in headspace of plant sample. The adsorbed compounds will release in thermal desorption system of GC. Head space (HS)solid phase microextraction (SPME) is a common passive sample preparation method for plant volatiles (Deasy et al., 2016; Dettmer and Engewald, 2002; Kallenbach et al., 2014; Tholl et al., 2006). However, because low amounts of absorbent fiber (polydimethylsiloxane (PDMS)) are employed in SPME (less than $0.5 \mu \mathrm{l}$ ), stir bar sorptive extraction (SBSE) was subsequently developed, which employs a thicker volume of coating fiber on a stir bar to increase the capability and sensitivity of volatile sampling (Kallenbach et al., 2014). Kallenbach et al. (2015) proposed "silicone tubing" as a cheap, fast, high-throughput method for headspace sampling, and this method performed well in field experiments. In passive sampling methods, plant part enclose in a plastic or glass bag. This chamber alter humidity, temperature, and light spectrum around plant organs and subsequently change volatile emission. To address this limitation, direct-contact sorptive extraction were developed in which a magnetic PDMS coated stir bar held on leaf by a magnet (Kfoury et al., 2017). This method do not need any chamber and can be used in field condition. Passive volatile sampling methods could be adapt for root system. Volatiles can be sampled from soil headspace by SPME method. However, it is better to collect volatiles from the rhizosphere. Eilers et al. (2015) exploited two perforated polytetrafluoroethylene (PTFE) discs to make chamber in bottom of pot. Plant roots passed through the top disc entering the chamber and emitted volatiles from roots were trapped by PDMS tubes. Later, Deasy et al. (2016) insert some air permeable PTFE tubes around root to collect rhizosphere volatiles. SPME apparatuses were mounted on tubes allowing temporal root volatile sampling in field condition. In dynamic headspace sampling methods, air continuously pumped over plant headspace and volatiles traps and enriches in adsorbent materials such as active charcoal, Tenax, Carbotrap X and Carboxen. Dynamic sampling prevent headspace accumulation of volatiles that may have negative impact on plant volatile emission (Gallego et al., 2010; Giacomuzzi et al., 2016; Quintana-Rodriguez et al., 2015). In compared to air flow in open systems, closedloop-stripping-analysis is a dynamic sampling method employing a closed system which minimizes air contaminants and increase its ability to traps low amount of volatiles. However, this method need solvent extraction step and is unable to detect compounds that their mass is below solvent mass such as methanol, carbon dioxide, acetaldehyde and ethanol (Giacomuzzi et al., 2017). Some of dynamic 
sampling methods use adsorbent suitable for thermal desorption in GC. As different adsorbents have different affinity for volatile compounds it is better to use multiple layer of adsorbents in a multi-sorbent tube (Gallego et al., 2010).

There are two main disadvantages to the current GCMS method: 1) GC-MS takes precise snapshots of volatile profiles, but volatile organic compound (VOC) emission occurs dynamically in nature; and 2) GC-MS requires the use of heavy laboratory equipment which cannot be used in the field. To overcome the pitfalls of GC-MS and employ the technique under in situ conditions, Contreras et al. (2008) invented a portable GC-TMS, which was later improved by adding a dynamic needle trap system for online detection of plant volatiles (Beck et al., 2015). Beck et al. (2015) showed that this method could differentiate between damaged and healthy Centaurea solstitialis in the natural environment. Portable GC-MS could efficiently discriminate between stem rot and anthracnose diseases of mango using 1-pentanol and ethyl boronate as marker volatiles for stem rot and thujol as a marker of anthracnose (Moalemiyan et al., 2006). Aksenov et al. (2014) coupled differential mobility spectrometry (DMS) with GC to detect citrus greening disease in plants at early stages of disease development. The portable GC/DMS device proved more effective than qPCR in detecting the unculturable phloem-limiting bacterium Candidatus Liberibacter solanacearum in apples under field conditions. Other powerful real-time instruments such as selected ion flow tube (SIFT)-MS and proton transfer reaction (PTR)-MS are also available for analyzing plant volatiles. PTR-TOF-MS is more sensitive than SIFT-MS for real-time VOC detection (Biasioli et al., 2011; Materic et al., 2015). PTR-MS allows partial identification of volatiles and is a powerful tool for the rapid monitoring of changes in volatile emissions over time (Fig. 1). PTR-MS is more suitable for the detection of low molecular mass volatiles such as ethanol, methanol, and propanol than GC-MS (Portillo-Estrada et al., 2015); however, the lack of a capillary column in PTR-MS makes the technique unsuitable for separating isomeric analytes of the same molecular mass. Ruzsanyi and colleagues (2013) installed a $20 \mathrm{~cm}$ long multi-capillary column at the inlet of the PTR-TOFMS system, and this allowed the efficient separation and quantification of aldehydes with the same fragmentation pattern and separation of the isomeric ketones 3-heptanone and 2-methyl-3-hexanone. This method holds promise for the precise, non-invasive detection of MIPVs in near real time (Fig. 1).

Non-destructive detection of diseased plants through analysis of volatile profiles is likely to become widespread

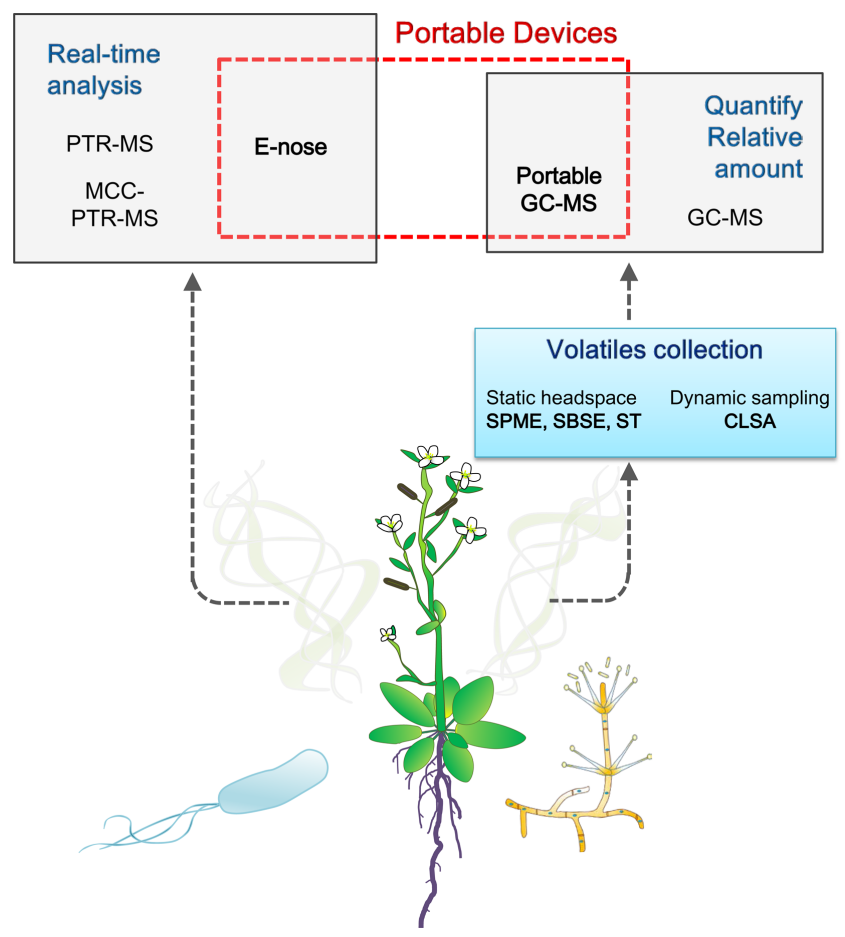

Fig. 1. Non-invasive diagnosis of microbial pathogenic infection and diseased plant tissues by volatile analysis. Volatile interpretation can be separated into two phases: 1. Volatile collection and 2. Volatile analysis. Analysis techniques include quantification of relative amounts of different volatiles and real-time analysis to assess ongoing changes. Volatile collection tools include dynamic sampling methods such as closed-loop-stripping-analysis (CLSA) and static headspace sampling methods such as solid phase microextraction (SPME), stir bar sorptive extraction (SBSE), and silicone tubing (ST). Quantification methods involve conventional gas chromatography-mass spectrometry (GC-MS) and portable GC-MS devices. Real-time analysis tools include Proton Transfer Reaction (PTR)-MS, multi-capillary column (MCC)-PTR-MS and E-nose. Two of these technologies, E-nose and portable GCMS, can be used in the field.

in modern agriculture. However, the heavy bench-top instruments that have been traditionally employed are not conducive to field, commercial greenhouse, or storage applications. In recent years, portable user-friendly devices such as E-nose, portable GC-MS, and GC/DMS have been developed to address this challenge (Fig. 1). The E-nose instrument contains an array of electronic chemical sensors, such as metal-oxide and conductive polymers, which change in their electrical conductivity upon interaction with volatiles. These conductivity changes can then be assessed by multivariate analysis techniques such as principal component analysis and cluster analysis to differentiate between samples. The E-nose technology is thus able to differentiate between sample volatile profiles but is not designed 
to detect individual volatiles. Biondi et al. (2014) used Enose for detection of bacterial brown and ring rot in commercial potato storage conditions, with efficient detection of diseased tubers achieved in $90 \%$ of samples. E-nose was potentially able to detect a single infected asymptomatic tuber within a $10 \mathrm{~kg}$ box of healthy tubers (de Lacy Costello et al., 2000). E-nose can also be used in complex situations. Not only could the instrument discriminate plant species, but it was also able to distinguish between wounded, pestinfested, and pathogen-infected plants in experimental conditions (Laothawornkitkul et al., 2008). Cellini et al. (2016) assessed GC-MS, PTR-MS, and E-nose for early detection of fire blight on apple plants. E-nose was identified as the best technique for detection of disease plants but not for identification of volatiles. Overall, the E-nose is a simple, portable, easy-to-use device that can be used for early detection of stressed plants (Fig. 1).

Overall, researchers can choose appropriate methods in plant disease detection based on their criteria such as sensitivity, specificity, speed, in situ application, nondestructive and real-time application. Vast array of volatile analysis methods can provide high speed, non-invasive and in field detection of plant disease in early stage of disease development. But, molecular methods such as real-time PCR are quantitative and highly specific in detection of pathogen species. It is also noteworthy that volatiles emission is a dynamic phenomenon, under control of ecological stimulus and physiological conditions. Volatiles emission could be affected spatially and temporally by plant phenological stage, damage severity, circadian clock, type of plant-pathogen interaction and saprophytic colonization of necrotized tissues (Attaran et al., 2009; Giacomuzzi et al., 2017; Sharifi et al., 2018). So, standardization of sampling conditions has important role as same as choosing proper instrumental tools. It is just possible to compare results from same plant phonological stage in same diurnal time and same stage in disease development. This seem to be important issue in case of hemibiotrophic pathogens which have both biotrophic and necrotrophic interaction with plant.

Preparations of biogenic volatile compounds towards field application

Most research into the activities of plant-growth-promoting BVCs utilize a bipartite Petri dish (referred to as I-plate) design (Bailly and Weisskopf, 2012), with plants on one side of the plate and the emitter bacteria on the other side, both growing on MS media (Ryu et al., 2003). Several media have been used for growth of volatile-producing bacteria. In general, volatiles from bacteria grown on poor media enhance plant growth, whereas volatiles from bacteria grown on rich media inhibit plant growth (Asari et al., 2016; Blom et al., 2011). Bacteria produce $\mathrm{HCN}, \mathrm{H}_{2} \mathrm{~S}$, and $\mathrm{NH}_{3}$, all volatile nonorganic compounds, in glycine and protein-rich media, and these have inhibitory effects on plants (Piechulla and Schnitzler, 2016). However, these studies were all obtained using Petri dish tests, and production of BVCs in soil is affected by several factors such as nutrient and oxygen availability, $\mathrm{pH}$ and temperature of soil, soil texture (Effmert et al., 2012; Wheatley, 2002), and bacterial GacS/GacA regulatory system (Cheng et al., 2016; Ossowicki et al., 2017). Further studies are needed to evaluate the types and concentrations of BVCs or individual volatiles that improve plant growth under natural conditions. Park et al. (2015) designed an experiment to investigate the effects of volatiles under soil conditions. A single colony of Pseudomonas fluorescens SS101 was placed in a chamber at the bottom of a pot and the chamber was covered with a filter. The pot was filled with soil and tobacco seeds were sown. Volatiles produced by $P$. fluorescens approximately doubled the plant fresh weight in that experiment. The same experiment was performed on tomato plants (Tahir et al., 2017), and B. subtilis SYST2 BVCs significantly increased tomato growth and photosynthesis. Together, these results indicate that bacterial volatiles could be effective even under natural conditions.

Production of BVCs is affected by several environmental conditions. As a consequence, results from application of emitter bacteria in natural conditions are not always reproducible. Experimental application of pure volatiles can yield more reproducible results, though it should be noted that the plant growth activity of BVCs is usually concentration dependent. VOC concentrations can vary in the 30$200 \mathrm{ng} / \mathrm{g}$ range on different soil types (Minnich, 1993) and plants can sense and respond to trace amounts of volatiles at levels below 120 parts per trillion (Shiojiri et al., 2012). Some pure volatiles are active in this range (Piechulla et al., 2017). Ryu et al. (2003) showed that 100 ng of 2,3-butanediol was the optimum amount for increasing Arabidopsis leaf surface area. The effects of higher concentrations of 2,3-butanediol were not significantly different from those of water. A similar result was obtained for $0.63 \mathrm{ng}$ of indole (Yu and Lee, 2013), $50 \mathrm{ng}$ of 13-tetradecadien-1-ol (Park et al., 2015), and $0.75 \mu \mathrm{M}$ dimethylhexadecylamine (Velázquez-Becerra et al., 2011).Optimum concentrations are specific to each BVC/plant combination. For example, optimal concentrations of dimethyl hexadecylamine were not the same in sorghum and alfalfa (Castulo-Rubio et al., 2015; Velázquez-Becerra et al., 2011). Application of pure 
BVCs has been tested in the field. The pure volatiles 3-pentanol and 2-butanone increased fruit production in cucumber by 6- and 4-fold, respectively, under field conditions (Song and Ryu, 2013), and soaking seedlings in $1 \mathrm{mM}$ 3-pentanol enhanced pepper resistance to two pathogens under field conditions (Choi et al., 2014). These results indicate that plant growth-promoting rhizobacteria (PGPR) volatiles have great potential to enhance plant growth and health under field conditions. BVCs might thus be considered as emerging gaseous fertilizers in modern agriculture.

Volatiles generally have high vapor pressure and are highly diffusible in air and water (Chung et al., 2016), characteristics that are advantageous for intra- and inter-specific communications. However, these properties are the main challenges for creating formulations of BVCs that can be used in agricultural applications. Volatiles are unstable and prone to react with highly reactive chemicals, and also have a short half-life and evaporate rapidly under natural conditions (Bakry et al., 2016). However, long-term exposure to BVCs seems to be necessary for plants to induce beneficial effects (Xie et al., 2009).

(Micro) encapsulation. BVC formulations suitable for use in field applications do not appear to have been developed to date. However, other scientific disciplines have explored formulations of molecules with similar characteristics, such as pheromones and food flavorings, and these technologies could be easily adapted to develop effectives formulations of BVCs. Researchers and companies usually use encapsulation or microencapsulation methods to protect sensitive substances such as flavors and pheromones (Bakry et al., 2016). In these technologies, the active compounds are enclosed in a polymer shell or coat. Encapsulation can increase the half-life and stability of these compounds and can also impart slow-release properties and protection from oxidation, UV, evaporation, and microbial degradation (Bansode et al., 2010). Different methods can be used for the encapsulation of volatile compounds, such as emulsion extrusion, coacervation, and spray drying (Fig. 2) (Bansode et al., 2010; Bakry et al., 2016). During encapsulation, the active ingredient, a polymer, and an emulsifier in water solution are homogenized together to form an emulsion. Common polymers are alginate, gelatin, chitosan, starch, and carboxymethyl cellulose. This emulsion is subsequently used in different methods to produce capsules or microcapsules. In spray drying, the emulsion is rapidly sprayed into a gradient heat chamber. The outer layer of sprayed particles dries quickly, forming a coat that protects the active ingredient. However, use of this process for volatiles requires optimization as volatiles are sensitive to

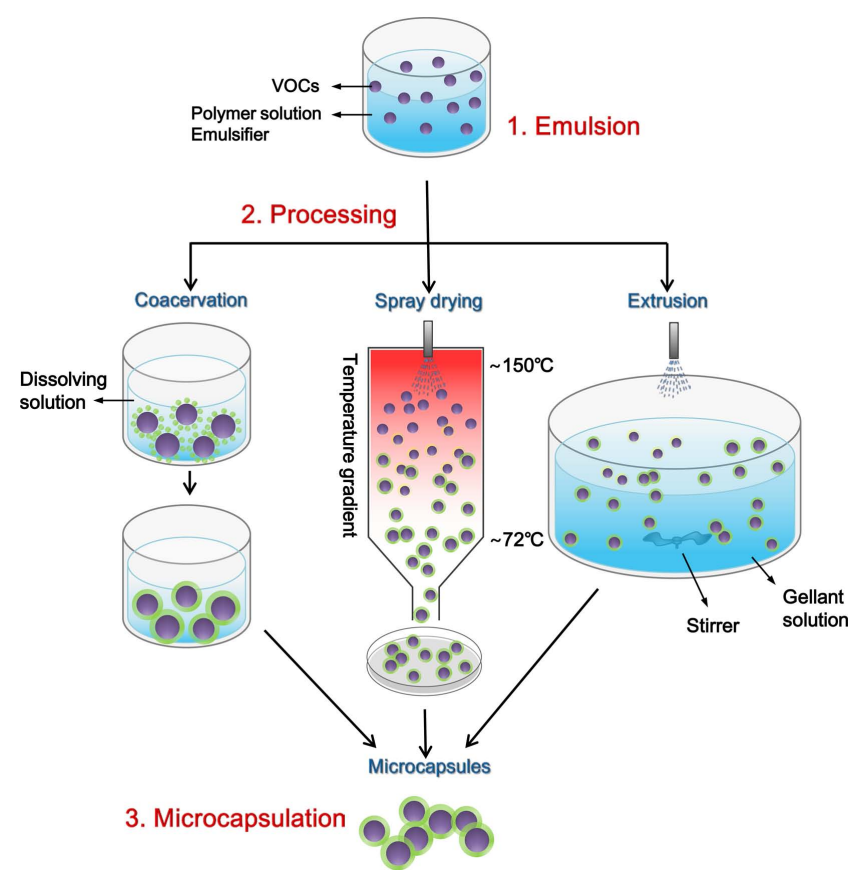

Fig. 2. Preparation of biogenic volatile compound formulations. There are three main steps in the preparation of volatiles for application to crop plants: 1. Emulsification, where an emulsion of volatiles, a polymer such as alginate, gelatin, or starch, and an emulsifier is prepared; 2 . Processing, where volatiles are coated with polymers by means of spray drying with heat, coacervation with dissolving compounds such as ethanol, or extrusion with cross-linking compounds such as $\mathrm{CaCl}_{2}$; and 3. Microcapsulation, where microcapsules are separated and dried for field applications.

high temperatures. Spray drying volatiles and optimization of the procedures is explained in the literature (Rosenberg et al., 1990; Soottitantawat et al., 2003). In the extrusion method, the emulsion is sprayed or dropped onto a crosslinking agent (gellan) solution, and polymers then form a layer around the active ingredients. These microcapsules are separated using methods such as vacuum separation with 0.4 micron filters. Common gellans are $\mathrm{CaCl}_{2}$ for alginate, $\mathrm{Al}_{2}\left(\mathrm{SO}_{4}\right)_{3}$ for carboxymethyl cellulose $(\mathrm{CMC})$, and tripolyphosphate for chitosan. The harvested microcapsules have nanopores at the surface that allow slow release of volatiles. For long-term storage, these pores can be partially sealed by temperature treatment (Fig. 2).

Encapsulation of the aphid attractant $\beta$-caryophyllene in alginate beads provided volatile release for 15 days under field conditions (Heuskin et al., 2012). Gelatin microencapsulation preserved basil essential oil under adverse storage conditions at $60^{\circ} \mathrm{C}$ for 49 days. Exposure to BVCs for periods less than 11 days were sufficient to elicit longterm beneficial effects on plant health (Ledger et al., 2016). 
In the coacervation method, two polymers with opposite charges such as gelatin and Arabic gum are added to the emulsion and the polymers are then deposited on the surface of the active ingredient particles. Reducing $\mathrm{pH}$ and temperature facilitates shell formation, and glutaraldehyde or formaldehyde can be used as cross-linking agent for hardening the microparticles (Xiao et al., 2014), after which microcapsules can be harvested. Coacervation is suitable for hydrophobic volatiles but is of limited use for hydrophilic compounds (Xiao et al., 2014). Coacervation is the most commonly used technology for microencapsulation of insect pheromones such as dodecanol and dodecyl acetate (Yu et al., 2012). When all technologies are considered, the extrusion method, especially using alginate, offers a cheap and easy production method, but spray drying is more suitable when large-scale production is needed (Bakry et al., 2016).

Sol-gel technology. Recently, researchers developed a new method, sol-gel technology, for microencapsulation of volatile compounds such as food flavorings. This method uses a matrix instead of beads. Alkoxide precursors such as tetraethoxysilane (TEOS) and tetramethoxy orthosilicate (TMOS) are hydrolyzed by water in the presence of an acid or base catalyzer to produce silanols. Silanols bind to each other to form siloxane molecules in a condensation reaction. In the next step, silanol and siloxane molecules bind to each other in the presence of an acid or base, and form a chain. Eventually, these chains form a matrix with small micropores (Buckley and Greenblatt, 1994). Sol-gel is a qualified formulation for controlled release of volatiles. The cross-linking in the sol-gel process can be managed to produce a formulation that allows a constant release rate. The concentration and type of precursor defines the size of matrix pores. Entrapping $(E)$-5-decenyl acetate as an insect pheromone in sol-gel provided constant slow release of this compound for 28 days with 14-45 $\mu \mathrm{g} /$ day. The best water/ TMOS concentration was $8: 1$, and the best emulsifier was PEG600 (Zada et al., 2009). Addition of polyvinyl alcohol as a co-polymer enhanced the slow-release properties of the sol-gel (Lei et al., 2015), and sol-gel with this co-polymer provided the best combination for optimizing long-term release of the insect volatile $N, N$-diethyl-2-methoxybenzamide (Chan et al., 2009).

\section{Application of biogenic volatile compounds as plant stimulant and protectant}

Field and small volume containers. Bead and matrix formulations both release volatiles in a continuous manner.
These formulations could be applied in the open field, in small volume transplant nurseries, and for fruit storage in small volume container. There are examples of application of plant volatiles and insect pheromones in field conditions. Microcapsule beads containing $E$ - $\beta$-farnesene and $E$ - $\beta$-caryophyllene attracted insects efficiently under field conditions (Heuskin et al., 2012), with release periods longer than 15 days. Peach twig borer insects were captured in traps baited with a sol-gel formulation of (E)-5-decenyl acetate under field conditions (Zada et al., 2009). The oriental fruit moth was controlled with a microcapsule formulation of $125 \mathrm{ml} /$ hectare of "MEC-OFM phase V" (Il'Ichev et al., 2006) where MEC-OFM phase $V$ was applied using a pesticide sprayer (Il'Ichev et al., 2006). Microcapsules of BVCs could be sprayed onto aerial plant parts with normal pesticide sprayers, but could also be inserted close to seeds in soil using standard seeders. The best option for volatile applications is small volume containers, such as fruit containers in storage and cold-frame nurseries that produce transplants such as tomato and rice. Volatiles from Streptomyces, Hypoxylon and Candida inhibit spoilage of several fruits in small fruit containers (Arrarte et al., 2017; Huang et al., 2011; Macías-Rubalcava et al., 2018; Wan et al., 2008). Volatiles of Streptomyces philanthi suppress Rhizoctonia solani on rice leaf segments in small containers (Boukaew et al., 2013). The effects of these volatile preparations are yet to be confirmed in transplant nurseries (Fig. 3).

Attract and kill formulations for pest control. Insects search for hosts for feeding and oviposition by means of plant volatile lures (Heil, 2014; Turlings and Erb, 2018). Herbivore-induced plant volatiles also attract parasitoid wasps (Kaplan, 2017; Turlings and Erb, 2018) and entomopathogenic nematodes (Rasmann et al., 2005) and fungi (Lin et al., 2016), a phenomenon termed 'cry for help'. Artificial blends of volatiles can be used to trap pests in the greenhouse and field (Bian et al., 2018; Cai et al., 2017). A combination of ( $Z$ )-3-hexenol, $(Z)$-3-hexenyl acetate, and linalool at a mass ratio of 0.6:23:12.6 was highly attractive to the tree leafhopper Empoasca onukii (Bian et al., 2018). Incorporation of commercial pesticides such as spinosad and thiodicarb with the attractive plant volatiles produces attracticide formulations (Martel et al., 2007). Conventional pesticide content can be reduced by more than $90 \%$ in these novel formulations (Martel et al., 2007). Odor backgrounds are present in the field, and it is necessary to exclude background volatiles in artificial attractive volatile blends (Cai et al., 2017). Attract and kill formulations must also be tested for their safety to non-target organisms, 


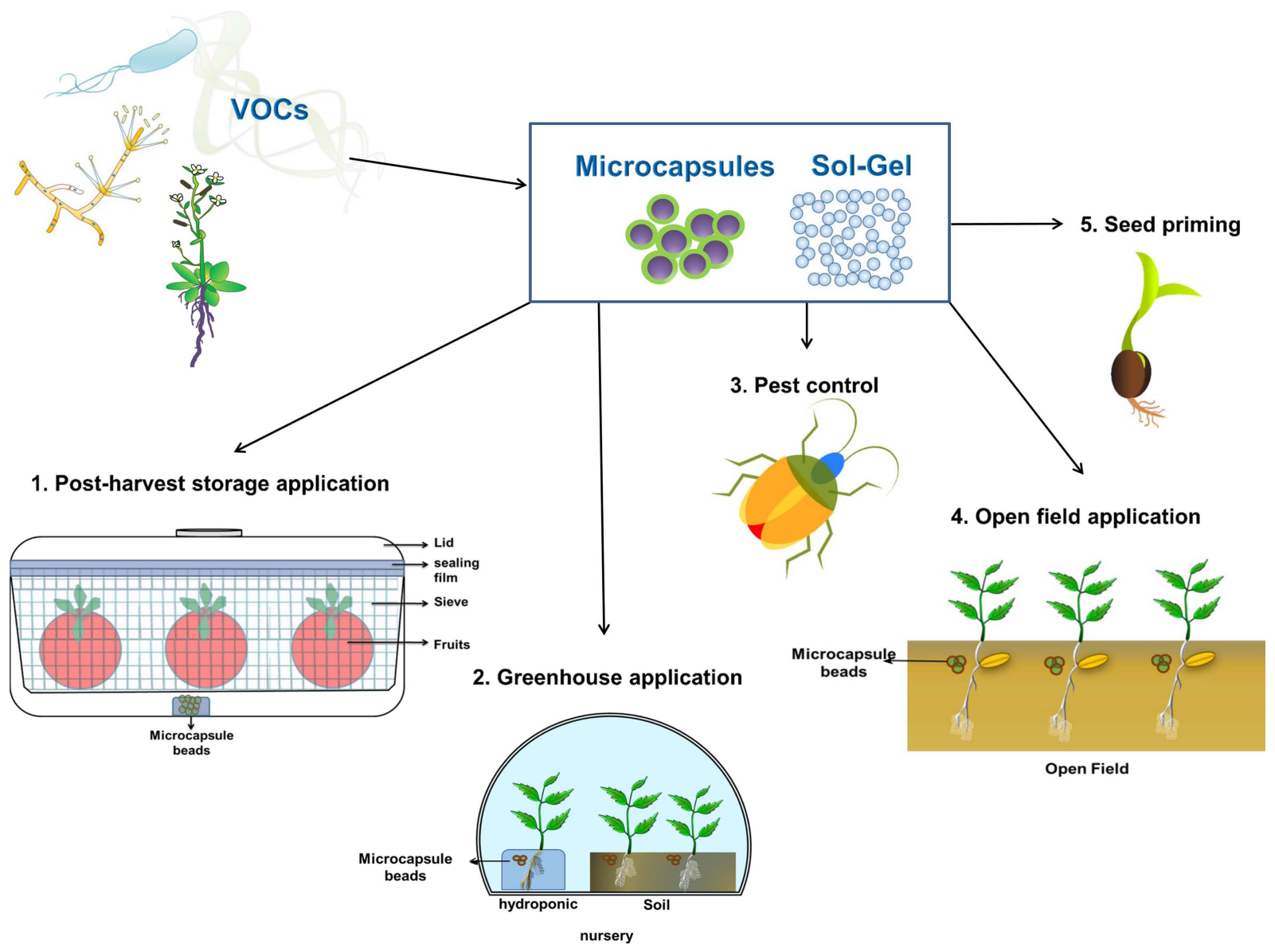

Fig. 3. Uses of biogenic volatiles in plant health applications. Microcapsule and sol-gel formulations of biogenic volatile compounds can be used in a range of situations: 1. Storage application; 2. Greenhouse application; 3. Insect pest control; 4. Open-field application; and 5. Seed priming.

particularly parasitoid wasps and honey bees, before their commercial development and release. Yazdani and Baker (2017) reported that the commercial attractive formulation Magnet ${ }^{\mathbb{R}}$ was not attractive to the parasitoid Diadegma semiclausum. However, plant volatiles are highly volatile and unstable and would benefit from application in slowrelease formulations. A sol-gel formulation of $(E)$-2-hexenal with an 8:2 ratio of TMOS:methyltrimethoxysilane (MTMOS) supported effective volatile release and attraction of black citrus aphid for 17 days (Bian et al., 2014). Attract and kill formulations are promising technologies that could allow effective control of plant pests while reducing impact on the environment and protecting human health (Fig. 3). In addition to attracticide formulations, plant volatiles can be used in the Push-Pull system or in artificial volatile dispensers to attractive parasitoids or repel herbivores (It is reviewed by Stenberg et al. (2015)) .

Chemigation. Like BVCs, agricultural fumigants such as methyl iodide, metham sodium, 1,3-dichloropropene, and methyl isothiocyanate have high vapor pressures (Ajwa et al., 2002). BVCs could therefore be applied using fumigant application methods such as shank injection to the soil. Recent research showed that drip irrigation of fumigants was more effective than shank injection (Ajwa et al., 2002; Zhu et al., 2011). This method, termed chemigation, could be used in crops grown on plastic mulch. BVCs under plastic mulch can easily diffuse to the soil and kill pathogens or be perceived by plants as infochemicals. Precise amounts of BVCs could be applied in chemigation systems by means of water flow meters and pressure regulators. Chemical injection units similar to those described by Zhu et al. (2011) could be used as the basis for development of more suitable systems for application of BVCs. Water solubility of BVCs is an important factor for chemigation. Several BVCs such as acetoin $(100 \mathrm{~g} / \mathrm{l})$, indole $(1.9 \mathrm{~g} / \mathrm{l})$, and dimethyl disulfide $(2.5 \mathrm{~g} / \mathrm{l})$ are highly soluble in water. For lipophilic compounds, emulsifiable concentrate formulations composed 
of a blend of active ingredient, organic solvent, and emulsifier may need to be developed for chemigation (Fig. 3). Seed priming. Seeds can be primed with BVCs. Seed priming with biological and chemical material is common practice in agriculture and horticulture. Primed seeds exhibit more uniform germination and emergence and are more resistant to biotic and abiotic stresses compared to untreated seeds (Jisha et al., 2013). Application of indole increased seed germination in Chinese cabbage by up to $40 \%$ in Petri dish conditions, indicating that BVCs have potential as priming agents (Yu and Lee, 2013). Further research is needed to determine the viability and practicality of this approach (Fig. 3).

\section{Perspectives}

Blends of volatile compounds can be biological indicators of the taxonomic position of an organism. However, the volatile blends produced by organisms also change in response to biotic and abiotic stresses. Conspecific neighbor and ecological counterpart species have learned to monitor the blends of volatile compounds and interpret the information therein during evolutionary history. If the language of volatile signals can be understood, these compounds can be exploited to improve agricultural productivity. Careful exploration of this chemical language is necessary to develop blends that are beneficial and non-harmful to the environment or human health. Safe applications include the noninvasive detection of plant diseases, but field applications of bacterial volatiles to control pests and diseases will require a more cautious approach. In conclusion, the chemical language of VOCs has great potential for exploitation in modern agriculture.

\section{Acknowledgments}

This work was supported by the Strategic Initiative for Microbiomes in Agriculture and Food, Ministry of Agriculture, Food and Rural Affairs, Republic of Korea (as part of the (multi-ministerial) Genome Technology to Business Translation Program) (918017-4) and the Advanced Biomass R\&D Center (ABC) of the Global Frontier Project funded by the Ministry of Science and ICT (ABC2015M3A6A2065697), and the KRIBB Initiative Program, South Korea.

\section{References}

Ajwa, H. A., Trout, T., Mueller, J., Wilhelm, S., Nelson, S. D., Soppe, R. and Shatley, D. 2002. Application of alternative fumigants through drip irrigation systems. Phytopathology 92:1349-1355.

Aksenov, A. A., Pasamontes, A., Peirano, D. J., Zhao, W., Dandekar, A. M., Fiehn, O., Ehsani, R. and Davis, C. E. 2014. Detection of Huanglongbing disease using differential mobility spectrometry. Anal. Chem. 86:2481-2488.

Arrarte, E., Garmendia, G., Rossini, C., Wisniewski, M. and Vero, S. 2017. Volatile organic compounds produced by Antarctic strains of Candida sake play a role in the control of postharvest pathogens of apples. Biol. Control 109:14-20.

Asari, S., Matzén, S., Petersen, M. A., Bejai, S. and Meijer, J. 2016. Multiple effects of Bacillus amyloliquefaciens volatile compounds: plant growth promotion and growth inhibition of phytopathogens. FEMS Microbiol. Ecol., 92:fiw070.

Attaran, E., Zeier, T. E., Griebel, T. and Zeier, J. 2009. Methyl salicylate production and jasmonate signaling are not essential for systemic acquired resistance in Arabidopsis. Plant Cell 21:954-971.

Bailly, A. and Weisskopf, L. 2012. The modulating effect of bacterial volatiles on plant growth: Current knowledge and future challenges. Plant Signal. Behav. 7:79-85.

Bakry, A. M., Abbas, S., Ali, B., Majeed, H., Abouelwafa, M. Y., Mousa, A. and Liang, L. 2016. Microencapsulation of oils: A comprehensive review of benefits, techniques, and applications. Compr. Rev. Food Sci. Food Saf. 15:143-182.

Bansode, S. S., Banarjee, S. K., Gaikwad, D. D., Jadhav, S. L. and Thorat, R. M. 2010. Microencapsulation: a review. Int. J. Pharm. Sci. Rev. Res. 1:38-43.

Beck, J. J., Porter, N., Cook, D. Gee, W. S., Griffith, C. M., Rands, A. D., Truong, T. V., Smith, L. and San Román, I. 2015. In-field volatile analysis employing a hand-held portable GC-MS: Emission profiles differentiate damaged and undamaged yellow starthistle flower heads. Phytochem. Anal. 26:395-403.

Bian, L., Sun, X. L., Cai, X. M. and Chen, Z. M. 2014. Slow release of plant volatiles using sol-gel dispensers. J. Econ. Entomol. 107:2023-2029.

Bian, L., Cai, X. M., Luo, Z. X., Li, Z. Q., Xin, Z. J. and Chen, Z. M. 2018. Design of an attractant for Empoasca onukii (Hemiptera: Cicadellidae) based on the volatile components of fresh tea leaves. J. Econ. Entomol. 111:629-636.

Biasioli, F., Yeretzian, C., Märk, T. D., Dewulf, J. and Van Langenhove, H. 2011. Direct-injection mass spectrometry adds the time dimension to (B)VOC analysis. Trends Anal. Chem. 30:1003-1017.

Biondi, E., Blasioli, S., Galeone, A., Spinelli, F., Cellini, A., Lucchese, C. and Braschi, I. 2014. Detection of potato brown rot and ring rot by electronic nose: From laboratory to real scale. Talanta 129:422-430.

Blom, D., Fabbri, C., Connor, E. C., Schiestl, F. P., Klauser, D. R., Boller, T., Eberl, L. and Weisskopf, L. 2011. Production of plant growth modulating volatiles is widespread among rhizosphere bacteria and strongly depends on culture conditions. Environ. Microbiol. 13:3047-3058. 
Boukaew, S., Plubrukam, A. and Prasertsan, P. 2013. Effect of volatile substances from Streptomyces philanthi RM-1-138 on growth of Rhizoctonia solani on rice leaf. BioControl 58:471-482.

Buckley, A. M. and Greenblatt, M. 1994. The sol-gel preparation of silica gels. J. Chem. Educ. 71:599-603.

Cai, X., Bian, L., Xu, X., Luo, Z., Li, Z. and Chen, Z. 2017. Field background odour should be taken into account when formulating a pest attractant based on plant volatiles. Sci. Rep. 7:41818.

Castulo-Rubio, D. Y., Alejandre-Ramírez, N. A., del Carmen Orozco-Mosqueda, M., Santoyo, G., Macías-Rodríguez, L. I. and Valencia-Cantero, E. 2015. Volatile organic compounds produced by the rhizobacterium Arthrobacter agilis UMCV2 modulate Sorghum bicolor (strategy II plant) morphogenesis and SbFRO1 transcription In Vitro. J. Plant Growth Regul. 34:611-623.

Cellini, A., Biondi, E., Blasioli, S., Rocchi, L., Farneti, B., Braschi, I., Savioli, S., Rodriguez-Estrada, M., Biasioli, F. and Spinelli, F. 2016. Early detection of bacterial diseases in apple plants by analysis of volatile organic compounds profiles and use of electronic nose. Ann. Appl. Biol. 168:409-420.

Chan, A. S., del Valle, J., Lao, K., Malapit, C., Chua, M. and So, R. C. 2009. Evaluation of silica Sol-Gel microcapsule for the controlled release of insect repellent, N,N-Diethyl2-methoxybenzamide, on Cotton. Philipp. J. Sci. 138:13-21.

Cheng, X., Cordovez, V., Etalo, D. W., van der Voort, M. and Raaijmakers, J. M. 2016. Role of the GacS sensor kinase in the regulation of volatile production by plant growth-promoting Pseudomonas fluorescens SBW25. Front. Plant Sci. 7:1706.

Choi, H. K., Song, G. C., Yi, H. S. and Ryu, C. M. 2014. Field evaluation of the bacterial volatile derivative 3-pentanol in priming for induced resistance in pepper. J. Chem. Ecol. 40:882-892.

Chung, J. H., Song, G. C. and Ryu, C. M. 2016. Sweet scents from good bacteria: Case studies on bacterial volatile compounds for plant growth and immunity. Plant Mol. Biol. 90:677-687.

Contreras, J. A., Murray, J. A., Tolley, S. E., Oliphant, J. L., Tolley, H. D., Lammert, S. A., Lee, E. D., Later, D. W. and Lee, M. L. 2008. Hand-portable gas chromatograph-toroidal ion trap mass spectrometer (GC-TMS) for detection of hazardous compounds. J. Am. Soc. Mass Spectrom. 19:1425-1434.

de Lacy Costello, B. P. J., Ewen, R. J., Gunson, H. E., Ratcliffe, N. M. and Spencer-Phillips, P. T. N. 2000. The development of a sensor system for the early detection of soft rot in stored potato tubers. Meas. Sci. Technol. 11:1685.

Deasy, W., Shepherd, T., Alexander, C. J., Birch, A. N. and Evans, K. A. 2016. Development and validation of a SPME-GC-MS Method for In situ passive sampling of root volatiles from glasshouse-grown broccoli plants undergoing below-ground herbivory by larvae of cabbage root fly, Delia radicum L. Phytochem. Anal. 27:375-393.
Dettmer, K. and Engewald, W. 2002. Adsorbent materials commonly used in air analysis for adsorptive enrichment and thermal desorption of volatile organic compounds. Anal. Bioanal. Chem. 373:490-500.

Effmert, U., Kalderás, J., Warnke, R. and Piechulla, B. 2012. Volatile mediated interactions between bacteria and fungi in the soil. J. Chem. Ecol. 38:665-703.

Eilers, E. J., Pauls, G., Rillig, M. C., Hansson, B. S., Hilker, M. and Reinecke, A. 2015. Novel set-up for low-disturbance sampling of volatile and non-volatile compounds from plant roots. J. Chem. Ecol. 41:253-266.

Gallego, E., Roca, F. J., Perales, J. F. and Guardino, X. 2010. Comparative study of the adsorption performance of a multisorbent bed (Carbotrap, Carbopack X, Carboxen 569) and a Tenax TA adsorbent tube for the analysis of volatile organic compounds (VOCs). Talanta 81:916-924.

Giacomuzzi, V., Cappellin, L., Khomenko, I., Biasioli, F., Schutz, S., Tasin, M., Knight, A. L. and Angeli, S. 2016. Emission of volatile compounds from apple plants infested with Pandemis heparana larvae, antennal response of conspecific adults, and preliminary field trial. J. Chem. Ecol. 42:1265-1280.

Giacomuzzi, V., Cappellin, L. Nones, S., Khomenko, I., Biasioli, F., Knight, A. L. and Angeli, S. 2017. Diel rhythms in the volatile emission of apple and grape foliage. Phytochemistry 138:104-115.

Halbfeld, C., Baumbach, J. I., Blank, L. M. and Ebert, B. E. 2018. Multi-capillary Column Ion Mobility Spectrometry of Volatile Metabolites for Phenotyping of Microorganisms. In: Synthetic Metabolic Pathways: Methods and Protocols, eds. by M. K. Jensen and J. D. Keasling, pp. 229-258. Springer New York, NY, USA.

Heil, M. 2014. Herbivore-induced plant volatiles: targets, perception and unanswered questions. New Phytol. 204:297-306.

Heuskin, S., Lorge, S., Lognay, G., Wathelet, J.-P., Béra, F., Leroy, P., Haubruge, E. and Brostaux, Y. 2012. A semiochemical slow-release formulation in a biological control approach to attract hoverflies. J. Environ. Ecol. 3:72-85.

Huang, R., Li, G. Q., Zhang, J., Yang, L. Che, H. J., Jiang, D. H. and Huang, H. C. 2011. Control of postharvest Botrytis fruit rot of strawberry by volatile organic compounds of Candida intermedia. Phytopathology 101:859-869.

Il'Ichev, A. L., Stelinski, L. L., Williams, D. G. and Gut, L. J. 2006. Sprayable microencapsulated sex pheromone formulation for mating disruption of oriental fruit moth (Lepidoptera: Tortricidae) in Australian peach and pear orchards. J. Econ. Entomol. 99:2048-2054.

Jansen, R. M., Wildt, J., Kappers, I. F., Bouwmeester, H. J., Hofstee, J. W. and van Henten, E. J. 2011. Detection of diseased plants by analysis of volatile organic compound emission. Annu. Rev. Phytopathol. 49:157-174.

Jiang, Y., Ye, J., Veromann, L. L. and Niinemets, U. 2016. Scaling of photosynthesis and constitutive and induced volatile emissions with severity of leaf infection by rust fungus (Melampsora larici-populina) in Populus balsamifera var. suaveolens. 
Tree Physiol. 36:856-872.

Jisha, K., Vijayakumari, K. and Puthur, J. T. 2013. Seed priming for abiotic stress tolerance: an overview. Acta Physiol. Plant. 35:1381-1396.

Kallenbach, M., Oh, Y., Eilers, E. J., Veit, D., Baldwin, I. T. and Schuman, M. C. 2014. A robust, simple, high-throughput technique for time-resolved plant volatile analysis in field experiments. Plant J. 78:1060-1072.

Kallenbach, M., Veit, D., Eilers, E. J. and Schuman, M. C. 2015. Application of silicone tubing for robust, simple, highthroughput, and time-resolved analysis of plant volatiles in field experiments. Bio-protocol 5:e1391.

Kaplan, I. 2017. A cry for help or sexual perfumes? An alternative hypothesis for wasp attraction to the scent of caterpillarwounded plants. Plant Cell Environ. 40:327-329.

Kfoury, N., Scott, E., Orians, C. and Robbat, A. Jr. 2017. Direct contact sorptive extraction: a robust method for sampling plant volatiles in the field. J. Agric. Food Chem. 65:85018509.

Laothawornkitkul, J., Moore, J. P., Taylor, J. E., Possell, M., Gibson, T. D., Hewitt, C. N. and Paul, N. D. 2008. Discrimination of plant volatile signatures by an electronic nose: A potential technology for plant pest and disease monitoring. Environ. Sci. Technol. 42:8433-8439.

Ledger, T., Rojas, S., Timmermann, T., Pinedo, I., Poupin, M. J., Garrido, T., Richter, P., Tamayo, J. and Donoso, R. 2016. Volatile-mediated effects predominate in Paraburkholderia phytofirmans growth promotion and salt stress tolerance of Arabidopsis thaliana. Front. Microbiol. 7:1838.

Lei, Y., Popplewell, L. M. and Huang, X. 2015. Microcapsules containing active ingredients. Google Patents: pp: US20150164751A20150164751.

Lin, Y., Hussain, M., Avery, P. B., Qasim, M., Fang, D. and Wang, L. 2016. Volatiles from plants induced by multiple aphid attacks promote conidial performance of Lecanicillium lecanii. PLoS One 11:e0151844.

Lough, F., Perry, J. D., Stanforth, S. P. and Dean, J. R. 2017. Detection of exogenous VOCs as a novel in vitro diagnostic technique for the detection of pathogenic bacteria. Trends Anal. Chem. 87:71-81.

Macías-Rubalcava, M. L., Sánchez-Fernández, R. E., RoqueFlores, G., Lappe-Oliveras, P. and Medina-Romero, Y. M. 2018. Volatile organic compounds from Hypoxylon anthochroum endophytic strains as postharvest mycofumigation alternative for cherry tomatoes. Food Microbiol. 76:363-373.

Martel, J. W., Alford, A. R. and Dickens, J. 2007. Evaluation of a novel host plant volatile-based attracticide for management of Colorado potato beetle, Leptinotarsa decemlineata (Say). Crop Protect. 26:822-827.

Martinelli, F., Scalenghe, R., Davino, S., Panno, S., Scuderi, G., Ruisi, P., Villa, P., Stroppiana, D., Boschetti, M., Goulart, L. R., Davis, C. E. and Dandekar, A. M. 2015. Advanced methods of plant disease detection. A review. Agron. Sustain. Dev. 35:1-25.
Materic, D., Bruhn, D., Turner, C., Morgan, G., Mason, N. and Gauci, V. 2015. Methods in plant foliar volatile organic compounds research. Appl. Plant Sci. 3:1500044.

Minnich, M. 1993. Behavior and determination of volatile organic compounds in soil: A literature review. U.S. Environmental Protection Agency, Washington, D.C., EPA/600/R-93/140 (NTIS PB94100153). URL https://cfpub.epa.gov/si/si_public_record_Report.cfm?Lab=ORD\&dirEntryID $=45050$.

Mithöfer, A. and Boland, W. 2016. Do you speak chemistry? Small chemical compounds represent the evolutionary oldest form of communication between organisms. EMBO Rep. 17:626-629.

Moalemiyan, M., Vikram, A., Kushalappa, A. and Yaylayan, V. 2006. Volatile metabolite profiling to detect and discriminate stem-end rot and anthracnose diseases of mango fruits. Plant Pathol. 55:792-802.

Niinemets, U., Kännaste, A. and Copolovici, L. 2013. Quantitative patterns between plant volatile emissions induced by biotic stresses and the degree of damage. Front. Plant Sci. 4:262.

Niinemets, Ü. and Monson, R. K. 2013. Biology, controls and models of tree volatile organic compound emissions. 5th ed. Springer Netherlands. 547 pp.

Ossowicki, A., Jafra, S. and Garbeva, P. 2017. The antimicrobial volatile power of the rhizospheric isolate Pseudomonas donghuensis P482. PLoS One 12: 0174362.

Park, Y. S., Dutta, S., Ann, M., Raaijmakers, J. M. and Park, K. 2015. Promotion of plant growth by Pseudomonas fluorescens strain SS101 via novel volatile organic compounds. Biochem. Biophys. Res. Commun. 461:361-365.

Piechulla, B. and Schnitzler, J. P. 2016. Circumvent $\mathrm{CO}_{2}$ effects in volatile-based microbe-plant interactions. Trends Plant Sci. 21:541-543.

Piechulla, B., Lemfack, M. C. and Kai, M. 2017. Effects of discrete bioactive microbial volatiles on plants and fungi. Plant Cell Environ. 40:2042-2067.

Portillo-Estrada, M., Kazantsev, T., Talts, E., Tosens, T. and Niinemets, Ü. 2015. Emission timetable and quantitative patterns of wound-induced volatiles across different leaf damage treatments in Aspen (Populus Tremula). J. Chem. Ecol. 41:1105-1117.

Quintana-Rodriguez, E., Morales-Vargas, A. T., Molina-Torres, J., Ádame-Alvarez, R. M., Acosta-Gallegos, J. A. and Heil, M. 2015. Plant volatiles cause direct, induced and associational resistance in common bean to the fungal pathogen Colletotrichum lindemuthianum. J. Ecol. 103:250-260.

Rasmann, S., Kollner, T. G., Degenhardt, J., Hiltpold, I., Toepfer, S., Kuhlmann, U., Gershenzon, J. and Turlings, T. C. J. 2005. Recruitment of entomopathogenic nematodes by insectdamaged maize roots. Nature 434:732-737.

Rosenberg, M., Kopelman, I. J. and Talmon, Y. 1990. Factors affecting retention in spray-drying microencapsulation of volatile materials. J. Agric. Food Chem. 38:1288-1294.

Ruzsanyi, V., Fischer, L., Herbig, J., Ager, C. and Amann, A. 2013. Multi-capillary-column proton-transfer-reaction time- 
of-flight mass spectrometry. J. Chromatogr. A 1316:112-118.

Ryu, C. M. 2015. Bacterial Volatiles as Airborne Signals for Plants and Bacteria. In: Principles of Plant-Microbe Interactions, ed. by B. Lugtenberg, pp. 53-61. Springer, Switzerland.

Ryu, C. M., Farag, M. A., Hu, C. H., Reddy, M. S., Wei, H. X., Pare, P. W. and Kloepper, J. W. 2003. Bacterial volatiles promote growth in Arabidopsis. Proc. Natl. Acad. Sci. U.S.A. 100:4927-4932.

Sharifi, R. and Ryu, C. M. 2016. Are bacterial volatile compounds poisonous odors to a fungal pathogen Botrytis cinerea, alarm signals to Arabidopsis seedlings for eliciting induced resistance, or both? Front. Microbiol. 7:196.

Sharifi, R. and Ryu, C. M. 2018a. Revisiting bacterial volatilemediated plant growth promotion: Lessons from the past and objectives for the future. Ann. Bot. 122:349-358.

Sharifi, R. and Ryu, C. M. 2018b. Sniffing bacterial volatile compounds for healthier plants. Curr. Opin. Plant Biol. 44:88-97.

Sharifi, R., Lee, S. M. and Ryu, C. M. 2018. Microbe-induced plant volatiles. New Phytol. 220:684-691.

Shiojiri, K., Ozawa, R., Matsui, K., Sabelis, M. W. and Takabayashi, J. 2012. Intermittent exposure to traces of green leaf volatiles triggers a plant response. Sci. Rep. 2:378.

Song, G. C. and Ryu, C. M. 2013. Two volatile organic compounds trigger plant self-defense against a bacterial pathogen and a sucking insect in cucumber under open field conditions. Int. J. Mol. Sci. 14:9803-9819.

Song, G. C., Choi, H. K. and Ryu, C. M. 2015. Gaseous 3-pentanol primes plant immunity against a bacterial speck pathogen, Pseudomonas syringae pv. tomato via salicylic acid and jasmonic acid-dependent signaling pathways in Arabidopsis. Front. Plant Sci. 6:821.

Soottitantawat, A., Yoshii, H., Furuta, T., Ohkawara, M. and Linko, P. 2003. Microencapsulation by spray drying: Influence of emulsion size on the retention of volatile compounds. J. Food Sci. 68:2256-2262.

Spinelli, F., Cellini, A., Vanneste, J. L., Rodriguez-Estrada, M. T., Costa, G., Savioli, S., Harren, F. J. M. and Cristescu, S. M. 2012. Emission of volatile compounds by Erwinia amylovora: biological activity in vitro and possible exploitation for bacterial identification. Trees 26:141-152.

Stenberg, J. A., Heil, M., Ahman, I. and Bjorkman, C. 2015. Optimizing crops for biocontrol of pests and disease. Trends Plant Sci. 20:698-712.

Tahir, H. A., Gu, Q., Wu, H., Raza, W., Hanif, A., Wu, L., Colman, M. V. and Gao, X. 2017. Plant growth promotion by volatile organic compounds produced by Bacillus subtilis SYST2. Front. Microbiol. 8:171.

Tholl, D., Boland, W., Hansel, A., Loreto, F., Rose, U. S. and Schnitzler, J. P. 2006. Practical approaches to plant volatile analysis. Plant J. 45:540-560.

Turlings, T. T. C. and Erb, M. 2018. Tritrophic interactions mediated by herbivore-induced plant volatiles: Mechanisms, ecological relevance, and application potential. Annu. Rev. Entomol. 63:433-452.

Velázquez-Becerra, C., Macías-Rodríguez, L. I., López-Bucio, J., Altamirano-Hernández, J., Flores-Cortez, I. and ValenciaCantero, E. 2011. A volatile organic compound analysis from Arthrobacter agilis identifies dimethylhexadecylamine, an amino-containing lipid modulating bacterial growth and Medicago sativa morphogenesis in vitro. Plant Soil 339:329340.

Wan, M., Li, G., Zhang, J., Jiang, D. and Huang, H. C. 2008. Effect of volatile substances of Streptomyces platensis F-1 on control of plant fungal diseases. Biol. Control 46:552-559.

Wheatley, R. E. 2002. The consequences of volatile organic compound mediated bacterial and fungal interactions. Antonie van Leeuwenhoek 81:357-364.

Wilson, A. D., Lester, D. G. and Oberle, C. S. 2004. Development of conductive polymer analysis for the rapid detection and identification of phytopathogenic microbes. Phytopathology 94:419-431.

Wittgenstein, L. 1922. Logisch-Philosophische Abhandlung. Kegan Paul.

Xiao, Z., Liu, W., Zhu, G., Zhou, R. and Niu, Y. 2014. A review of the preparation and application of flavour and essential oils microcapsules based on complex coacervation technology. $J$. Sci. Food Agric. 94:1482-1494.

Xie, X., Zhang, H. and Pare, P. W. 2009. Sustained growth promotion in Arabidopsis with long-term exposure to the beneficial soil bacterium Bacillus subtilis (GB03). Plant Signal. Behav. 4:948-953.

Yazdani, M. and Baker, G. 2017. A plant volatile-based attractant formulation is not attractive to Diadegma semiclausum (Hymenoptera: Ichneumonidae). Aust. Entomol. 57:359-364.

Yi, H. S., Heil, M., Adame-Alvarez, R. M., Ballhorn, D. J. and Ryu, C. M. 2009. Airborne induction and priming of plant defenses against a bacterial pathogen. Plant Physiol. 151:21522161.

Yu, S. M. and Lee, Y. H. 2013. Plant growth promoting rhizobacterium Proteus vulgaris JBLS202 stimulates the seedling growth of Chinese cabbage through indole emission. Plant Soil 370:485-495.

Yu, Y. T., Liu, L. N., Zhu, X. L. and Kong, X. Z. 2012. Microencapsulation of dodecyl acetate by complex coacervation of whey protein with acacia gum and its release behavior. Chin. Chem. Lett. 23:847-850.

Zada, A., Falach, L. and Byers, J. A. 2009. Development of solgel formulations for slow release of pheromones. Chemoecology 19:37-45.

Zhu, H., Wang, X., Reding, M. E. and Locke, J. C. 2011. Distribution of chemical and microbial pesticides delivered through drip irrigation systems. In: Pesticides - Formulations, Effects, Fate, ed. by M. Stoytcheva, pp. 155-180. InTech, Croatia. 